Priestley, M., Biesta, G.J.J., Philippou, S. \& Robinson, S. (2015). The teacher and the curriculum: exploring teacher agency. In D. Wyse, L. Hayward \& J. Pandya (Eds.), The SAGE Handbook of Curriculum, Pedagogy and Assessment. London: SAGE Publications Ltd

\title{
The teacher and the curriculum: exploring teacher agency
}

\author{
Mark Priestley, Gert Biesta, Stavroula Philippou and Sarah Robinson
}

\begin{abstract}
A key debate in the curriculum field has centred on the extent to which teachers should or could achieve agency over the curriculum they enact. Threats to teacher agency have come from top-down control of curricula, either through input regulation (prescription of content, methods and/or teaching materials) or output regulation (steering through outcomes). Drawing upon an ecological model to explore the concept of teacher agency, this chapter will illustrate through empirical research conducted in Scotland and Cyprus, how it manifests in various ways through teachers' work. The chapter concludes with a discussion of why it is important to understand and take into account teacher agency when formulating and developing curriculum policy.
\end{abstract}

Keywords

Teacher agency; professional agency; teacher autonomy; curriculum policy; curriculum change; curriculum regulation; curriculum enactment

\section{Introduction}

Teachers seem to matter once more - albeit for a range of different reasons. This is a significant change from several decades of policies that have actively deprofessionalized teachers through highly prescriptive curricula and strict regimes of inspection and control (Priestley and Biesta, 2013). This trend was clearly exemplified by England's landmark National Curriculum (DES, 1989), which heralded unprecedented levels of government control over curriculum content and teaching methodology. Such ideas have been attractive to policymakers in other countries: the National Curriculum's linear model, with prescribed content set out as objectives organized into levels, was 
Priestley, M., Biesta, G.J.J., Philippou, S. \& Robinson, S. (2015). The teacher and the curriculum: exploring teacher agency. In D. Wyse, L. Hayward \& J. Pandya (Eds.), The SAGE Handbook of Curriculum, Pedagogy and Assessment. London: SAGE Publications Ltd

subsequently copied elsewhere, to at least some extent (see, e.g., the New Zealand Curriculum Framework, Ministry of Education, 1993; Scotland's 5-14 Curriculum, Scottish Executive, 2000; and for a critique e.g. Kelly, 1990; Lawton, 1996). This sort of approach constructs teachers as technicians following preset procedures and allowing only limited teacher agency in curriculum-making (Taylor 2013).

There has been a growing realization, however, that ultimately it is not possible to have a teacherproof curriculum since teachers mediate the curriculum in ways which are often antithetical to policy intentions, leading to an implementation gap and often to unintended consequences (see, e.g., Cuban, 1998; Osborn et al., 1997; Supovitz, 2008). Recent discourses driving global education policy have instead talked up the important role of the teacher in enacting curriculum policy, with a renewed emphasis on the important role of teachers as the most significant within-school influence on school improvement (OECD, 2005; McKinsey \& Co., 2007). Such discourses have been accompanied by at least three parallel trends within education policies in many countries.

First, there is an emerging tendency to construct teachers explicitly as agents of change (e.g. Goodson, 2003; Priestley, 2011a; Nieveen, 2011). The last ten years have witnessed the development of new forms of national curricula and curriculum policy in a range of countries (Sinnema and Aitken, 2013), including Scotland and the Republic of Cyprus, the two countries that provide the contexts for our analysis in this chapter. Intrinsic to these developments is a renewed vision of teachers as active developers of curriculum. In Scotland, for example, the new Curriculum:

aims to engage teachers in thinking from first principles about their educational aims and values and their classroom practice [...] through a climate in which reflective practitioners share and develop ideas. (Scottish Executive, 2006: 4)

Similarly, the Republic of Cyprus has witnessed a comprehensive reform of the curriculum, at the launch of which teachers were re-envisioned as 'autonomous or relatively autonomous professionalpedagogue[s]' (Ministry of Education and Culture, 2004: 16), signaling an intention to break away 
Priestley, M., Biesta, G.J.J., Philippou, S. \& Robinson, S. (2015). The teacher and the curriculum: exploring teacher agency. In D. Wyse, L. Hayward \& J. Pandya (Eds.), The SAGE Handbook of Curriculum, Pedagogy and Assessment. London: SAGE Publications Ltd

from the tradition of them as implementers of others' decisions, towards a position of 'relative autonomy in curriculum development and teaching at the micro-level of the school unit and the classroom' (ibid.: 20).

A second trend lies in education policies which strongly emphasize the need to improve the quality of teachers through programmes of continuous professional formation, for instance in the form of teacher professional learning communities (Stoll et al., 2005) or new teacher standards and calls for teaching to become a master's level profession. In Scotland, such discourses are strongly reflected in the report Teaching Scotland's Future (Donaldson, 2010). Donaldson asserted that:

The most successful educating systems invest in developing their teachers as reflective, accomplished and enquiring professionals who are able to teach successfully in relation to current expectations, but who have the capacity to engage fully with the complexities of education and to be key actors in shaping and leading educational change. (ibid.: 14)

This trend is also visible in the Cyprus reform, where discourses about teacher professional development have shifted from a focus on state-initiated, centralized practice, towards becoming a matter of teachers' 'self-education,' 'self-development,' and 'self-improvement' (Ministry of Education and Culture, 2004: 114), signaling increased attention towards individual and school-based professional development as key for the reform's success.

The abovementioned trends are nonetheless problematic for a number of reasons, in large part due to a third emerging trend, which is an increasing emphasis in many countries on accountability systems and the use of metrics to measure educational effectiveness (Biesta, 2009, 2010). At a rhetorical level at least, the first two trends suggest a [re]turn to bottom-up approaches that put the teacher at the centre of the educational process, following years of prescriptive, top-down teacher-proof curricula. However, it is highly debatable whether the rhetoric of autonomy is borne out in practice. Whereas tight curricular prescription of content appears to have become less prevalent in many countries, this move away from prescription has been matched by an increase in the frequency and extent of output 
Priestley, M., Biesta, G.J.J., Philippou, S. \& Robinson, S. (2015). The teacher and the curriculum: exploring teacher agency. In D. Wyse, L. Hayward \& J. Pandya (Eds.), The SAGE Handbook of Curriculum, Pedagogy and Assessment. London: SAGE Publications Ltd

regulation, for example through school inspections and the evaluative use of attainment data (Kuiper et al., 2013). This 'giving with one hand and taking away with the other' (Leat, 2013) has arguably done more to erode teacher autonomy than was the case under former, ostensibly more prescriptive approaches (Biesta, 2004). It has been associated with the development of performative cultures in school and instrumental decision-making by teachers (Ball, 2003; Wilkins, 2011), as teachers distance themselves from their personal values in order to 'play the game' (Gleeson and Gunter, 2001). This game can take the form of fabrication of the school's image - careful impression management and discourses of excellence (Keddie et al., 2011) and the concealing of 'dirty laundry' (Cowie et al., 2007) - as well as more serious corruption and cheating (Sahlberg, 2010). Ethical and professional practices thus lose out to performative pressures, as survival strategies lead to tactical and even cynical compliance (Biesta, in press). Performativity has been well-documented in Scotland (Cowie et al., 2007; Leat et al., 2013). However, it is relatively absent in Cyprus, where there is no tradition of driving school effectiveness through attainment data or external inspections, and where curriculum regulation has traditionally been of the input variety in the form of state produced school textbooks used in the place/as substitutes of curricular documents for over a century (Philippou, 2014).

Nevertheless, we note that a rhetoric of standards, benchmarking and effectiveness, present since 1997, has been recently rekindled following the publication of Cyprus's (poor) results at TIMMS and PISA and two reports by the World Bank (2014a; 2014b; see: Klerides and Philippou, forthcoming 2015).

We would argue that the tensions described above are serious, creating difficult dilemmas and powerful perceptions of risk for teachers as they develop the curriculum in their schools. We would further argue that it is problematic for policy to demand that teachers exercise agency in their working practices, and then simultaneously deny them the means to do so, effectively disabling them. Moreover, we emphasize that while such policies tend to overtly focus on the individual dimensions of what it means to be an effective teacher, it neglects due consideration of (and even actively distorts) the cultural and structural conditions that play important roles in enabling teachers to achieve agency in their work (see Priestley, Biesta and Robinson, 2015). 
Priestley, M., Biesta, G.J.J., Philippou, S. \& Robinson, S. (2015). The teacher and the curriculum: exploring teacher agency. In D. Wyse, L. Hayward \& J. Pandya (Eds.), The SAGE Handbook of Curriculum, Pedagogy and Assessment. London: SAGE Publications Ltd

It is within this complex terrain that the concept of teacher agency is helpful. It has emerged in recent literature as an alternative means of understanding how teachers might enact practice and engage with policy (e.g. Lasky, 2005; Leander and Osbourne, 2008; Ketelaar et al., 2012; Pyhältö et al., 2012; Priestley et al., 2013). The concept of teacher agency itself is not unproblematic: agency remains an inexact and poorly conceptualized construct in much of the literature about teaching. In particular, it is often not clear whether the term refers narrowly to an individual capacity of teachers - which would fit with policy agendas to improve the quality of teaching - or more broadly to an emergent 'ecological' phenomenon dependent upon the quality and nature of individuals' engagement with their environments (Biesta and Tedder, 2007). This latter conception is more helpful in our view, as it allows questions to be posed about the conditions under which, and the means by which, teachers are able to achieve agency in their everyday practices. Teacher agency has been regularly linked to narrow agendas of school improvement, where agency is construed more narrowly as 'change agentry' (Fullan, 2003). Yet in such discourses, teachers remain positioned as implementers of someone else's policy, and schools are invariably represented as being in deficit and in need of reform.

In this chapter, we offer an ecological conceptualisation of agency that emphasizes the importance of both agentic capacity and contextual conditions in shaping agency and in which the achievement of agency is seen as a temporal process (Emirbayer and Mische, 1998). In the chapter we outline why this conceptualization of teacher agency is both a useful construct for enabling a deeper understanding of teaching as a professional field, as well as a conceptual tool with the potential to facilitate the future development of better educational policy for shaping school improvement efforts. In particular, we raise important questions about the relative balance between input and output regulation (Kuiper et al., 2013; Leat et al., 2013), and their various impacts on teacher agency. We start with an overview of this theorization of agency, before drawing on several empirical studies from two contexts - Scotland and Cyprus - to illustrate how teacher agency is shaped, in what (archetypal) forms it manifests itself, and in what ways this subsequently shapes practice ${ }^{1}$. We conclude the chapter by reflecting on how education policy might contribute more constructively to teacher agency, and on how there might be 
Priestley, M., Biesta, G.J.J., Philippou, S. \& Robinson, S. (2015). The teacher and the curriculum: exploring teacher agency. In D. Wyse, L. Hayward \& J. Pandya (Eds.), The SAGE Handbook of Curriculum, Pedagogy and Assessment. London: SAGE Publications Ltd

an alternative framing of curricular purposes and processes within policy (Biesta, 2009), or in other words: a framework of specification that enables rather than constrains the development of constructive curricular practices by teachers (Kuiper et al., 2013).

\section{Theorizing teacher agency}

Agency

A key point in our ecological approach (Priestley et al., 2015) lies in our ambition to understand the phenomenon of agency itself, rather than in explaining agency's role in shaping and determining social action, as is often found in sociological discussions of agency. In this way we are able to ask how agency is 'achieved' in concrete settings and under particular 'ecological' conditions and circumstances (Biesta and Tedder, 2006). This perspective therefore differs from the sociological concept of agency as a variable in social action (for example in the longstanding structure/agency debate: see Bunzell, 2008).

Rather than seeing agency as residing in individuals as a property or capacity, the ecological view sees agency as an emergent phenomenon.

[T]his concept of agency highlights that actors always act by means of their environment rather than simply in their environment [so that] the achievement of agency will always result from the interplay of individual efforts, available resources and contextual and structural factors as they come together in particular and, in a sense, always unique situations. (Biesta and Tedder, 2007: 137; emph. added).

Agency, in other words, is not something that people have; it is something that people do or, more precisely, something they achieve (Biesta and Tedder, 2006). It denotes a 'quality' of the engagement of actors with temporal-relational contexts-for-action, not a quality of the actors themselves. Viewing agency in such terms helps us to understand how humans are able to be reflexive and creative, acting 
Priestley, M., Biesta, G.J.J., Philippou, S. \& Robinson, S. (2015). The teacher and the curriculum: exploring teacher agency. In D. Wyse, L. Hayward \& J. Pandya (Eds.), The SAGE Handbook of Curriculum, Pedagogy and Assessment. London: SAGE Publications Ltd

counter to societal constraints, but also how individuals are enabled and constrained by their social and material environments.

A second key point is that agency is both temporal and relational. We draw here on Emirbayer and Mische (1998), who point to the theoretical one-sidedness of existing theories of agency which, in their view, tend to focus either on routine, or on purpose, or on judgement. They make a case for a theory of agency which encompasses the dynamic interplay between these three dimensions and which takes into consideration 'how this interplay varies within different structural contexts of action' (1998: 963). For this reason they suggest that the achievement of agency should be understood as a configuration of influences from the past, orientations towards the future and engagement with the present. They refer to these three dimensions as the iterational, the projective and the practical-

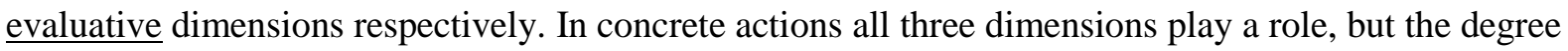
to which they contribute varies. This is why Emirbayer and Mische speak of a 'chordal triad of agency within which all three dimensions resonate as separate but not always harmonious tones' (1998: 972; emphasis in original).

Emirbayer's and Mische's ideas are helpful because they show that agency doesn't come from nowhere, but builds upon past achievements, understandings and patterns of action. This is expressed in the iterational element of agency which has to do with 'the selective reactivation by actors of past patterns of thought and action, routinely incorporated in practical activity, thereby giving stability and order to social universes and helping to sustain identities, interactions, and institutions over time' (1998: 971; emph. in original). A key word here is 'selective'. Emirbayer and Mische note that while some writers suggest that 'the agentic reactivation of schemes inculcated through past experience tends to correspond to (and thus reproduce) societal patterns' (1998: 981), this level of routinization does not have to be the case. Actors do not always act from habit, following routinized patterns of behaviour, but are able to recognize, appropriate and refashion past patterns of behaviours and experience as they seek to manoeuvre among repertoires in dealing with present dilemmas and engage in expectation maintenance in their orientations to the future. A key implication here, is that actors 
Priestley, M., Biesta, G.J.J., Philippou, S. \& Robinson, S. (2015). The teacher and the curriculum: exploring teacher agency. In D. Wyse, L. Hayward \& J. Pandya (Eds.), The SAGE Handbook of Curriculum, Pedagogy and Assessment. London: SAGE Publications Ltd

who are able to draw upon a rich repertoire of experience might be expected to be able to develop more expansive orientations to the future and draw upon a greater range of responses to the dilemmas and problems of the present context, than might be the case with their more experientially impoverished compatriots.

Emirbayer and Mische's approach also acknowledges that agency is 'motivated'; it is linked to the intention to bring about a future that is different from the present and the past. This is encapsulated in the projective element of agency which encompasses 'the imaginative generation by actors of possible future trajectories of action, in which received structures of thought and action may be creatively reconfigured in relation to actors' hopes, fears, and desires for the future' (1998: 971., emph. in original). Such a process of continual imaginative reconstruction of the future involves 'draw[ing] upon past experiences in order to clarify motives, goals and intentions, to locate possible future constraints, and to identify morally and practically appropriate courses of action' (1998: 989). An implication here is that people who are able to form expansive projections about their future trajectories might be expected to achieve greater levels of agency than those whose aspirations are more limited, at least to the extent that they have access to a wider repertoire of alternative futures. Whether such a repertoire is translated into action does, of course, not only depend on the repertoire itself but also on the contextual conditions under which teachers act.

Although agency is involved with the past and the future, it can only ever be 'acted out' in the present, which is what is expressed in the practical-evaluative dimension: 'the capacity of actors to make practical and normative judgements among alternative possible trajectories of action, in response to the emerging demands, dilemmas, and ambiguities of presently evolving situations' (1998: 971, emph. in original). Judgements are both practical - shaped by the affordances and constraints of the context - and evaluative - for example judgements of risk in any give situation or judgement in relation to views about what is educationally desirable. Emirbayer's and Mische's analysis emphasizes the importance of context and structure in that agency is seen as the 'temporally constructed engagement with different structural environments' (1998: 970). The combination of 
Priestley, M., Biesta, G.J.J., Philippou, S. \& Robinson, S. (2015). The teacher and the curriculum: exploring teacher agency. In D. Wyse, L. Hayward \& J. Pandya (Eds.), The SAGE Handbook of Curriculum, Pedagogy and Assessment. London: SAGE Publications Ltd

context and time highlights that it is not only important to understand agency in terms of the individual's lifecourse. It is at the very same time important to understand transformations of contexts-for-action over time. According to Emirbayer and Mische, such contexts are primarily to be understood as social contexts in that agency is 'always a dialogical process by and through which actors immersed in temporal passage engage with others within collectively organized contexts of action' (1998: 974). However, we would argue that such contexts are also material, in that agency is also shaped by the availability of physical resources and the nature of physical constraints.

\section{Teacher agency}

While agency per se has been extensively theorized, teacher agency has not received the attention it deserves. There has been little explicit research or theory development (Vongalis-Macrow, 2007) about this 'vague' concept (Pyhältö et al., 2012 ) and existing change models tend to both underplay and misconstrue the role of teacher agency in educational innovation (as noted by Leander and Osborne, 2008). In this section of the chapter we briefly set out our ecological model for understanding teacher agency, drawing explicitly on the temporal/relational conception of agency outlined in the previous section. The diagram below represents the key dimensions of the model, illustrating the ways in which we analytically separate out key elements of each dimension. With regard to the iterational dimension we distinguish between the influence of the more general life histories of teachers and their more specific professional histories (which include both their own education as a teacher and the accumulated experience of being a teacher). With regard to the projective dimension we distinguish between short term and long[er] term orientations of action. And with regard to the practical-evaluative dimension we make a distinction between cultural, structural and material aspects - the various components of the present contexts which provide the conditions and affordances through which agency is achieved by teachers. These affordances are both practical (i.e. what is possible given the resources and constraints of the context) and evaluative (e.g. subject to judgements of risk). 
Priestley, M., Biesta, G.J.J., Philippou, S. \& Robinson, S. (2015). The teacher and the curriculum: exploring teacher agency. In D. Wyse, L. Hayward \& J. Pandya (Eds.), The SAGE Handbook of Curriculum, Pedagogy and Assessment. London: SAGE Publications Ltd

Figure one: Teacher agency

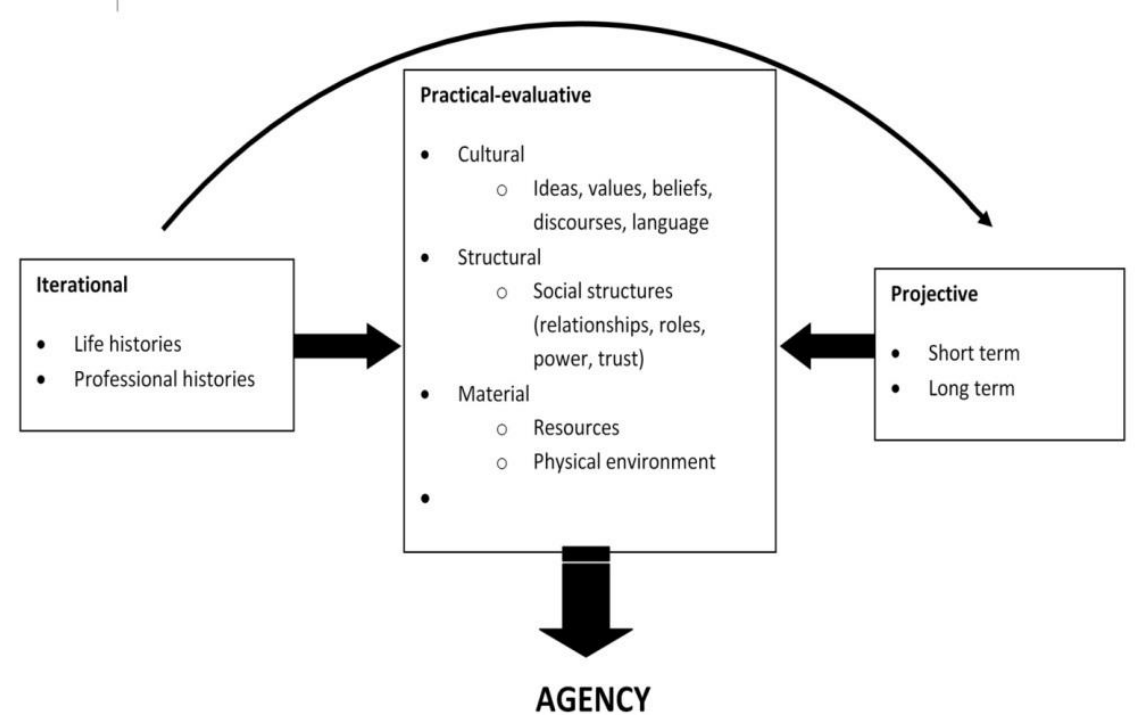

(First published in Priestley et al., 2013)

The model highlights that the achievement of agency is always informed by past experience - and in the particular case of teacher agency this concerns both professional and personal experience. The model also emphasizes that the achievement of agency is always orientated towards the future in some combination of short[er] term and long[er] term objectives and values. And it illustrates that agency is always enacted in a concrete situation, therefore, both constrained and supported by cultural, structural and material resources available to actors.

In the following sections of the chapter we present a number of different examples of agency from the aforementioned empirical studies.

\section{Teacher agency in practice}

In both countries upon which we draw, the context of teaching is subject to the curricular reforms introducing more teacher autonomy, new modes of teaching and learning and new expectations upon teachers. The following examples show how teachers are able to achieve agency in the face of what are often conflicting demands; they also illustrate clearly that teacher agency is multi-faceted and complex. The initial discussion focuses on teachers who might be called, after Osborn et al. (1997), 
Priestley, M., Biesta, G.J.J., Philippou, S. \& Robinson, S. (2015). The teacher and the curriculum: exploring teacher agency. In D. Wyse, L. Hayward \& J. Pandya (Eds.), The SAGE Handbook of Curriculum, Pedagogy and Assessment. London: SAGE Publications Ltd

'creative mediators' - those who have the (personal and professional) experiences, skills and knowledge to act in ways that exploit the permissiveness of new curricular models, despite difficult and/or uncertain conditions. However, we reiterate that we do not see agency as an innate personal capacity, which means that what teachers bring to the situation is only one dimension in the overall achievement of agency. As the discussion progresses, we also examine teachers who achieve agency in narrowly instrumental ways, or who achieve less agency in the same difficult and/or uncertain conditions. We conclude the discussion with an analysis of how those conditions might be altered or shaped to afford more constructive and expansive forms of agency.

\section{Creative mediation}

The curricular reform in Cyprus placed teachers outside of their usual comfort zones, working in new and often unfamiliar ways, especially with regards to the expectation that teachers in primary schools would create their own curricula rather than follow the state textbooks (see Kontovourki et al., forthcoming 2015 for an overview). In some cases, dealing with ambiguity involved a proactive degree of adaptation, along the lines of what Osborn et al. (1997) have termed 'creative mediation'. Such mediation of policy often required considerable ingenuity and imagination. In the Curriculum Change and Teacher Professionalism project in Cyprus, we noted how in 2010-11, when the new curriculum was first introduced to teachers, they often positioned themselves as reformers and implementers (see Philippou et al., 2014). These positionings emerged even when implementation became mandatory in 2012-2013, as some teachers found this policy to be 'liberating', legitimating new approaches conducive to their existing ideas and values about education and curriculum, allowing them to 'return' to the ethical or social or child-centred 'mission' of the teaching profession, towards what they believed education in general and in the long-run should be about. For these teachers, a combination of a rich and varied prior experience of teaching as well as the legitimation provided by a more permissive curriculum, and the comparative absence of a performative, attainment-driven culture, opened up new spaces for agency. The following quotation illustrates this.. 
Priestley, M., Biesta, G.J.J., Philippou, S. \& Robinson, S. (2015). The teacher and the curriculum: exploring teacher agency. In D. Wyse, L. Hayward \& J. Pandya (Eds.), The SAGE Handbook of Curriculum, Pedagogy and Assessment. London: SAGE Publications Ltd

I needed a lot of effort on my behalf to decide which texts children would finally work with. Ehm, ok, we started reluctantly, the unit was organized by the children. Most of the workload was with the teacher, so that the unit was structured-sequenced in a way that all children would be able to respond. We had included articles from newspapers, interviews from various agents or films from YouTube with scenes of violence [during football matches]. They took the position of certain people, anyway, [...] for empathy. [...] children were asked to compare the three points of view [of the football match spectator, of the coach, of the player] and anyway not to passively accept these views [...]. They had many creative activities, they made posters, ehm, they created scenarios and acted them out. It was really good. It lasted for three weeks. I confess these were three of the most tiring weeks that I remember so far [in my career] but it was really so good. (teacher, Cyprus)

Even though curriculum enactment as described above was expected in the context of the new Language curriculum (which rendered it distinct from other subject-areas in which curriculum policy was more restrictive; Kontovourki, 2015), some teachers did not just comply but creatively mediated the official policy when viewing it as a real opportunity to perform the profession 'autonomously' beyond the constraining ways in which it had traditionally been construed. When teachers achieved agency through creative mediation, they tended to believe that the official curriculum should be created, or at least adapted, in relation to the children in their class, and that children should participate in the selection of topics and materials. This last element, however, was at other times in tension with other pedagogical ideals of the teachers, when such materials brought in by pupils were 'inappropriate' or of 'poor' pedagogical value to them. There was also concern that the new curriculum could encourage social inequalities if observed in full, since teachers were aware that some children didn't have access or the support at home to find and select such materials. To address such tensions teachers 'filtered' materials brought into the classroom or protected certain children who had been unable to contribute by bringing in additional material themselves (see Philippou et al., 2014). 
Priestley, M., Biesta, G.J.J., Philippou, S. \& Robinson, S. (2015). The teacher and the curriculum: exploring teacher agency. In D. Wyse, L. Hayward \& J. Pandya (Eds.), The SAGE Handbook of Curriculum, Pedagogy and Assessment. London: SAGE Publications Ltd

\section{Life experience and agency}

The previous examples suggest that teachers' prior experiences plays an important role in their achievement of agency, enabling them to develop expansive aspirations in relation to their teaching and to enhance their access to cultural resources as they deal with dilemmas and problems in their day to day professional lives. A particular example from the Cultures of Curriculum Making in School and College study in Scotland (Priestley et al., 2012), illustrates starkly the differences that two individuals, with quite different biographies, might bring to bear on the same teaching context. In this case, a Science teacher, Donald, who was the original participant in the study, was replaced (due to absence from work through illness) by a relief teacher, Debbie. Donald typified the career trajectory of many secondary school teachers, moving from school to a university degree, to post-graduate teacher education, before taking up a teaching post. Debbie, in contrast, had a very different background.

I used to be an agricultural biologist .... and I had my kids and then I did some voluntary work in schools and then some ... er ... special educational needs stuff in playgroups and primary, and then up here as an auxiliary and then changed. (teacher, Scotland)

There were differences in their respective approaches to teaching, and in the agency that they were able to achieve. Donald's approach was more overtly framed around traditional patterns of schooling, shaped by Donald's 'career trajectory formed primarily within educational institutions' (2012: 208) narrowly transmissive, focused on future assessments and engaging students through 'edutainment' (the teacher being a good laugh and a performer). Donald's teaching tended to be influenced by continual demands within the school to raise attainment and he appeared to lack the breadth of experience to act or think otherwise in the face of ongoing pressures and a school-wide culture of performativity; his agency was consequently limited as he tended to 'go with the flow'.

Debbie exhibited a far more expansive range of aspirations, shaped by her more varied life and professional experience, partly outside of educational institutions and settings. Her educational views emphasized a purposeful and principled approach to her teaching, often enacted through classroom 
Priestley, M., Biesta, G.J.J., Philippou, S. \& Robinson, S. (2015). The teacher and the curriculum: exploring teacher agency. In D. Wyse, L. Hayward \& J. Pandya (Eds.), The SAGE Handbook of Curriculum, Pedagogy and Assessment. London: SAGE Publications Ltd

dialogue, based on a belief that students had innate potential, to be unlocked by the teacher. This was a marked contrast to the student deficit views widely encountered during this study, and moreover represented a swimming against the tide in an environment where student attainment was considered to be the primary goal of schooling. We note here that another teacher in this study, Gerald, talked explicitly about slipping some education into his teaching occasionally, but only when time pressures permitted. These short vignettes illustrate how teachers' agency is shaped differently by their past experiences, in ways which afford different possibilities for action in their professional lives.

A second type of teacher agency, with clear roots in a distinctive and different career trajectory, is provided by the case of Jock, a participant in the Social Practices of Curriculum Making study in Scotland (Priestley, 2011b). In this case, the school's management had introduced a new integrated model of provision for Social Studies to replace the separate subject approach (Geography, History, Modern Studies). Jock, with previous experience of teaching integrated humanities in England, was a proponent of a pupil-centred approach to teaching, in contrast with many of his colleagues. He agreed with the broad thrust of the initiative, but disagreed with its mode of implementation (through an authoritarian top-down prescription), and the relentless focus on raising attainment through transmissive pedagogies.

I think the attitude towards senior management and myself changed significantly because perhaps of my attitude, my background, the way I teach and I'm quite outspoken these days if I'm asked my opinion; if I'm not, I tend not to give it anymore because I don't think it's really welcome. It's a very autocratic management ... I will work with democratic decisions ... I do know that even in the authority that there are better, more open, less hard management styles that (are) more effective. (teacher, Scotland)

Jock's opposition to the school's management had detrimental effects on his career, leading to him being overlooked for promotion and becoming relatively marginalized in the school decision-making processes. We would argue here that his actions are indicative of a high level of agency, framed around strong beliefs about the nature of education, and formed through a rich and varied experience 
Priestley, M., Biesta, G.J.J., Philippou, S. \& Robinson, S. (2015). The teacher and the curriculum: exploring teacher agency. In D. Wyse, L. Hayward \& J. Pandya (Eds.), The SAGE Handbook of Curriculum, Pedagogy and Assessment. London: SAGE Publications Ltd

of teaching. Agency, in Jock's case, initially had strong iterational and projective dimensions, but his exercise of this agency - he was not a teacher simply going with the flow - led over time to reduced opportunities to achieve agency. This case provides a good example of agency changing over time, as the teacher's resistance subsequently led to a closing down of his options and, particularly, a withdrawal of the relational resources previously afforded through senior management support for his actions.

\section{Strategic compliance}

Jock's actions impacted upon his achievement of agency, but other teachers choose to strategically comply with policy in the face of similar pressures. Strategic compliance with new curricular policy is a phenomenon regularly seen in the studies. This approach to implementing new policy clearly takes advantage of the permissive (or as some might say: ambiguous) nature of the new curricula. What is less clear is whether such actions are a result of agency, or whether they are simply the habitual reproduction of former modes of practice. The following quotations from some of the studies illustrate the phenomenon.

And this happens to many colleagues, many end up with this kind of thinking because it's what they say 'We can't crack [from pressure], how long should we try and see no fruition?' you go back to... what can be done in the way we knew for so many years that could be done. (teacher, Cyprus [Curriculum Change and Teacher Professionalism])

I think and you'll find it with most Scottish (subject deleted) departments that what we've done is adapted units of work we've been doing for years, you know. I mean these things are tried and tested and I don't have any qualms about doing that. (teacher, Scotland [Social Practices of Curriculum Making])

I can cover all of these assessment parts in one, with one project here, one short project. It's not exactly the way they are saying it, but you are not saying we can't do it this way. And it meets all the criteria. I can tick all the boxes quite confidently. [...] that is one thing that you 
Priestley, M., Biesta, G.J.J., Philippou, S. \& Robinson, S. (2015). The teacher and the curriculum: exploring teacher agency. In D. Wyse, L. Hayward \& J. Pandya (Eds.), The SAGE Handbook of Curriculum, Pedagogy and Assessment. London: SAGE Publications Ltd

can see with Curriculum for Excellence: that the rules aren't quite as strict; you can tweak them without feeling too guilty. (interview with teacher [Building Upon Success: extending and sustaining curriculum change in partnership with the Highland Council])

There are questions about the nature and extent of such agency. First, there are questions about whether such actions to subvert the intentions of curricular policy, whether intended or not, represent what might be termed 'good agency'. What, in other words, are the reference points against which such action can be justified. Second, there are questions about whether such actions stem from teachers achieving agency or whether it is a case of following the line of least resistance, avoiding difficult decisions about innovation and being largely rooted in habitual and routinized forms of practice from the past. We would suggest in these cases, that we are witnessing the latter to some extent, and that agency is thus limited. Absent from these cases is the sort of principled reflexivity that was so evident in the cases described in the previous section, where teachers developed practices that clearly went against the grain in their respective schools. In the examples quoted here we see mainly a desire to preserve the status quo, and little evidence of strong projections in relation to either new curricula or education more broadly.

Agency lost?

The above examples show how teachers are able to achieve agency in their work, both in ways which involve engaging constructively with policy and educational principles, and in ways which are more strategic. In the former cases, we see teachers taking the opportunity afforded by permissive policy to expand their teaching repertoires, and to act in accordance with deep-seated principles. In the latter cases, the same permissiveness is utilised to continue former practices. In the various studies, we have also seen many examples where agency is very much more limited - indeed comparatively absent. Such examples often relate to very experienced teachers, suggesting strongly that agency, in line with the ecological model, is not purely a case of high teacher capacity. It is also strongly influenced by the environment, particularly the availability of cultural, material and relational resources. For example, 
Priestley, M., Biesta, G.J.J., Philippou, S. \& Robinson, S. (2015). The teacher and the curriculum: exploring teacher agency. In D. Wyse, L. Hayward \& J. Pandya (Eds.), The SAGE Handbook of Curriculum, Pedagogy and Assessment. London: SAGE Publications Ltd

in Cyprus, the Curriculum Change and Teacher Professionalism study elicited the following responses:

...teachers were a bit lost, they didn't have any [teaching] material, so that they know how to work, the philosophy of the subject changed and not the subject-matter; there should have been exemplary-model lessons mainly [as professional development] so that the teacher could see how to approach the new philosophy. The subject-matter has not been reduced, all the teachers are making the same comment: that the subject-matter is too much, the time is little and they can't implement the new curricula as they would like. And the important thing is that there is no [teaching] material. (teacher, Cyprus)

Another Cypriot teacher suggested that the new curriculum was 'practically non-implementable and it makes you feel that you are not doing your job well'. The Scottish data is replete with similar statements. For example, Teacher Agency and Curriculum Change project (Priestley et al., 2013, 2015) data suggested that the teachers in one of the high schools did not achieve much agency. This was evident through repeated comments in interviews about a lack of confidence in engaging with the new curriculum:

It will be really difficult for the things that people want to know about. Like the Curriculum for Excellence, I can't think of anybody that's feeling like they are particularly in a position to be an expert and to help people. (teacher, Scotland)

Oh my goodness, that is a whole year and I don't know that I am any further forward with feeling confident about implementing Curriculum for Excellence. (teacher, Scotland)

What I don't know is how other people are doing it. So I'm still no further forward with that than I was when I first spoke to you. I'm just kind of doing my own thing and hoping that it's okay. (teacher, Scotland) 
Priestley, M., Biesta, G.J.J., Philippou, S. \& Robinson, S. (2015). The teacher and the curriculum: exploring teacher agency. In D. Wyse, L. Hayward \& J. Pandya (Eds.), The SAGE Handbook of Curriculum, Pedagogy and Assessment. London: SAGE Publications Ltd

These sentiments were evident across this particular school, where the research suggested lines of communication that were predominantly vertical, hierarchical and linear, accompanied by significant evidence of truncated and fragmented professional relationships and a high degree of professional isolation. In short, this was an environment where achieving agency was often difficult.

\section{Opening up space for teacher agency}

In this section we briefly explore how teacher agency might be afforded through a deliberate [re]shaping of the context within which and by means of which it is achieved. Specifically we are talking here about the practical-evaluative dimension of agency, which encompasses both the practical conditions for agency (affordances and constraints) as well as evaluative issues (such as judgments of risk). A key issue here is the availability of resources by means of which teachers achieve agency. We illustrate this discussion by considering one type of resource - the relational resources made available through the networks in which teachers were positioned socially. The discussion draws upon one of the secondary schools participating in the Teacher Agency and Curriculum Change study (Priestley et al., 2013, 2015). Here we noted that, despite strong similarities between this school and the other school described in the previous section - for example, a broadly similar range of beliefs and aspirations held by the teachers, similar buildings and material resources, the same district authority - there were striking differences between the teachers in terms of their agency which played out, for instance, in terms of enhanced levels of confidence as the teachers engaged with the new curriculum.

The research suggested that this might be in part attributed to the culture of the school. Interviewees talked about a culture where innovation and risk-taking was encouraged and supported, as well as a culture of sharing.

And if you are encouraging staff to do things that are a wee bit different or to not always follow things in a mainstream way, there is much more chance that they will develop as teachers, as professionals and as members of staff. So when someone comes with a crazy 
Priestley, M., Biesta, G.J.J., Philippou, S. \& Robinson, S. (2015). The teacher and the curriculum: exploring teacher agency. In D. Wyse, L. Hayward \& J. Pandya (Eds.), The SAGE Handbook of Curriculum, Pedagogy and Assessment. London: SAGE Publications Ltd

idea and says 'I want to try and do this with the second year class', okay, have a go at that ... If they make a mess of it and it does not work, well that is okay. 'You tried, it did not work, we will try something different next time'. (school senior manager, Scotland)

However, a more significant difference lay in the ways in which social relations were patterned in the school. First, there were strong informal relationships within the academic faculty researched, characterized by high levels of trust. Second, there was a strong push from the senior management to develop strong, reciprocal 'relationships within the school, so that staff get on well with staff, staff get on well with pupils and pupils get on with other pupils' (interview with senior manager). Some of these relationships were clearly vertical and formal, with a focus on the flow of information. Others were horizontal, both formal working groups as well as more informal connections, often growing organically out of short term needs. Such relationships helped teachers to develop their practice and solve day to day dilemma.

And we share in there what we are doing and good practice and things across these things. So we are all coming together at various points and saying how can we tackle this and what ideas have you got and how should we take this forward and how do you do this in your department. And trying to come up with a common code of skills, yeah. Core skills that we can all be promoting across the whole school (teacher, Scotland).

At this school there was a sense that such connections were burgeoning as a consequence of a proactive policy of fostering collegial, professional relationships, both within and across faculties.

\section{Conclusions}

An important implication of the idea that agency is achieved in the interaction between individuals and contexts rather than being solely about the capacity of actors, is that the importance of context should be taken more seriously by policymakers, as contexts may disable individuals with otherwise high agentic capacity. While teachers may come to a situation equipped with substantial capacity (e.g. skills and knowledge) and strong educational aspirations, they may encounter a context in which 
Priestley, M., Biesta, G.J.J., Philippou, S. \& Robinson, S. (2015). The teacher and the curriculum: exploring teacher agency. In D. Wyse, L. Hayward \& J. Pandya (Eds.), The SAGE Handbook of Curriculum, Pedagogy and Assessment. London: SAGE Publications Ltd

innovation may simply prove to be too difficult or too risky to enact. This also shows why the language of 'capacity building' is misleading as it seems to suggest that the key to teachers' agency solely lies with their capacity, rather than with the interplay of what teachers 'bring' to the situation and what the situation 'brings' to the teacher. Such conclusions have clear implications for those designing public policy, particularly when the goal is to enhance teacher agency, for example in relation to developing new curriculum. Public policy in respect of teacher development tends to focus on raising the capacity of teachers as individual actors; our view is that it needs to attend more explicitly to the cultural and structural domains which frame teachers' work.

A second implication lies in an observation by Emirbayer and Mische that what might pass for agency is not necessarily so. For example, agency may be involved in the reproduction of social patterns through active resistance to change, when superficially what seems to be occurring is habitual behaviour by the actors concerned, or a lack of agency in the face of insurmountable problems. By contrast, 'actors who feel creative and deliberative while in the flow of unproblematic trajectories' (Emirbayer and Mische, 1998: 1008) may not be achieving high levels of agency, as they simply go with the flow. The examples cited in this chapter illustrate how agency is much more than simply following unproblematic trajectories. This is an important implication when one considers the difference between autonomy and agency. Many critics of current policy advocate autonomy as a means of freeing up schools and enabling change. However, autonomy (understood here as a comparative absence of regulation) does not necessarily equate to agency. Teachers granted autonomy may simply fail to achieve agency as they, for example, habitually reproduce past patterns of behaviour, or as they lack cognitive and relational resources. Conversely, agency may be shaped and enhanced by policy that specifies goals and processes, enhancing the capability of teachers to manoeuvre between repertoires, make decisions and frame future actions.

In summary, therefore, the ecological approach to teacher agency offers considerable potential in enabling those who frame policies to more fully understand the implications of those policies for those who enact practice and who act in practice. It allows us to rigorously consider how the ecologies 
Priestley, M., Biesta, G.J.J., Philippou, S. \& Robinson, S. (2015). The teacher and the curriculum: exploring teacher agency. In D. Wyse, L. Hayward \& J. Pandya (Eds.), The SAGE Handbook of Curriculum, Pedagogy and Assessment. London: SAGE Publications Ltd

of teaching affect teacher decision-making and teacher actions. And it potentially enables teachers to become more reflexive about their professional working practices, as they take on responsibility for the long-term development of the students they work with. In achieving these goals, the concept of teacher agency in general, and the ecological approach in particular, potentially offers a means for arresting and even reversing twenty five years of misguided regulation of the work of teachers.

\section{Acknowledgment}

We wish to acknowledge the input of colleagues - Richard Edwards, Stavroula Kontovourki, Kate Miller, Sarah Minty, Eleni Theodorou - who, while not authors of this chapter, significantly contributed to the empirical and conceptual work underpinning our analysis.

\section{Footnote}

1. Space precludes a detailed description of each country context, over and above that provided in the introduction to the chapter. Additionally, readers should refer to the following referenced sources for more detail about the empirical research underpinning our analysis. In Scotland, data are drawn from four projects: The Social Practices of Curriculum-Making (Priestley, 2011b); Building Upon Success: extending and sustaining curriculum change in partnership with the Highland Council (funded by the Scottish Government: Priestley and Minty, 2012); Cultures of Curriculum Making in School and College (ESRC reference RES-000-22-2452: Priestley et al., 2012); and Teacher Agency and Curriculum Change (ESRC reference RES-000-22-4208: Priestley, Biesta and Robinson, 2013, 2015). The data collection for the Cyprus project, entitled Curriculum Change and Teacher Professionalism (Kontovourki et al., forthcoming 2015; Philippou et al., 2014; Philippou et al., in press), was conducted with the contribution of undergraduate and postgraduate students of the University of Cyprus in the Spring of 2013, and the data analysis was supported by funds from the same University.

\section{References}


Priestley, M., Biesta, G.J.J., Philippou, S. \& Robinson, S. (2015). The teacher and the curriculum: exploring teacher agency. In D. Wyse, L. Hayward \& J. Pandya (Eds.), The SAGE Handbook of Curriculum, Pedagogy and Assessment. London: SAGE Publications Ltd

Ball, S.J. (2003) The teacher's soul and the terrors of performativity, Journal of Education Policy, 18: 215-228.

Biesta, G.J.J. (2004) Education, accountability and the ethical demand. Can the democratic potential of accountability be regained?, Educational Theory, 54: 233-250.

Biesta, G.J.J. (2009) Good education in an age of measurement: On the need to reconnect with the question of purpose in education, Educational Assessment, Evaluation and Accountability 21: $33-46$.

Biesta, G.J.J. (2010) Good Education in an Age of Measurement. Boulder, CO: Paradigm Publishers.

Biesta, G.J.J. (in press) Education, measurement, and the professions: Reclaiming a space for democratic professionality in education, Educational Philosophy and Theory.

Biesta, G.J.J. and Tedder, M (2006) How is agency possible? Towards an ecological understanding of agency-as-achievement. Working paper 5. Exeter: The Learning Lives project.

Biesta, G.J.J. and Tedder, M. (2007) Agency and learning in the lifecourse: Towards an ecological perspective, Studies in the Education of Adults, 39: 132-149.

Bunzell, D. (2008) Agency-structure debate. In S. Clegg \& J.R. Bailey (eds.), International Encyclopedia of Organization Studies (pp. 47-50). London: Sage.

Cowie, M., Taylor, D. and Croxford, L. (2007) 'Tough, Intelligent Accountability’ in Scottish Secondary Schools and the role of Standard Tables and Charts (STACS): A Critical Appraisal, Scottish Educational Review, 39: 29-50.

Cuban, L. (1998) How schools change reforms: redefining reform success and failure, Teachers College Record, 99: 453-477. 
Priestley, M., Biesta, G.J.J., Philippou, S. \& Robinson, S. (2015). The teacher and the curriculum: exploring teacher agency. In D. Wyse, L. Hayward \& J. Pandya (Eds.), The SAGE Handbook of Curriculum, Pedagogy and Assessment. London: SAGE Publications Ltd

DES (Department of Education and Science) (1989) The National Curriculum: from policy to practice. London: HMSO.

Donaldson, G. (2010) Teaching Scotland's Future: report of a review of teacher education in Scotland. Edinburgh: Scottish Government.

Doyle, W. and Ponder, G.A. (1977) The Practicality Ethic in Teacher Decision-Making, Interchange, $8: 1-12$.

Emirbayer, M. and Mische, A. (1998) What is agency?, The American Journal of Sociology, 103: $962-1023$

Fullan, M. (2003) Change Forces with a Vengeance. London: RoutledgeFalmer.

Gleeson, D. and Gunter, H., (2001) The performing school and the modernisation of teachers, in D. Gleeson and C. Husbands (eds)The performing school: Managing, teaching and learning in a performance culture. London: RoutledgeFalmer. pp.139-158.

Goodson, I.F. (2003) Professional knowledge, professional lives. Maidenhead: Open University Press.

International Institute for Education Planning (1997) Appraisal study on the Cyprus education system. Paris: UNESCO.

Keddie, A., Mills, M. and Pendergast, D. (2011) Fabricating and identity in neo-liberal times: performing schooling as 'number one', Oxford Review of Education, 37: 75-92.

Kelly, A.V. (1990) The National Curriculum: A Critical Review. London: Paul Chapman Publishing.

Ketelaar, E., Beijaard, D., Boshuizen, H.P.A. and Den Brok, P.J. (2012) Teachers' positioning towards an educational innovation in the light of ownership, sense-making and agency, Teaching and Teacher Education, 28: 273-282. 
Priestley, M., Biesta, G.J.J., Philippou, S. \& Robinson, S. (2015). The teacher and the curriculum: exploring teacher agency. In D. Wyse, L. Hayward \& J. Pandya (Eds.), The SAGE Handbook of Curriculum, Pedagogy and Assessment. London: SAGE Publications Ltd

Klerides, E. and Philippou, S. (forthcoming 2015) A decade of reform? Exploring 'Cyprus education' since 2004, in T. Corner (ed), Education in the European Union. Vol. 2. London:

Bloomsbury.

Kontovourki, S. (2015) The constitution of language arts over the last decade in Cyprus (2004-2014): A reading/analysis of official discourse and discursive practices. Invited presentation at the Interdisciplinary Lecture Series 'Education, Society, \& Culture', Department of Education, European University-Cyprus. 17 March 2015. Nicosia, Cyprus. [in Greek]

Kontovourki, S., Theodorou, E. and Philippou, S. (forthcoming 2015) Governing teachers through curriculum reform in Cyprus: subjects or subjects? In H-G. Kothoff \& E. Klerides (Eds.).Governing educational spaces: knowledge, teaching, and learning in transition. Rotterdam: Sense Publishers.

Kuiper, W., Nieveen, N.and Berkvens, J. (2013) Curriculum regulation and freedom in the Netherlands - A puzzling paradox, in W.Kuiper and J. Berkvens (eds), Balancing Curriculum Regulation and Freedom across Europe, CIDREE Yearbook 2013. Enschede, the Netherlands: SLO. pp.139-162.

Lasky, S. (2005) A sociocultural approach to understanding teacher identity, agency and professional vulnerability in a context of secondary school reform, Teaching and Teacher Education, 21: 899-916.

Lawton, D. (1996) Beyond the National Curriculum. London: Hodder and Stoughton.

Leander, K.M. and Osborne, M.D. (2008) Complex positioning: Teachers as agents of curricular and pedagogical reform, Journal of Curriculum Studies, 40: 23-46.

Leat, D. (2014) Curriculum regulation in England: Giving with one hand and taking away with the other, European Journal of Curriculum Studies, 1: 69-74. 
Priestley, M., Biesta, G.J.J., Philippou, S. \& Robinson, S. (2015). The teacher and the curriculum: exploring teacher agency. In D. Wyse, L. Hayward \& J. Pandya (Eds.), The SAGE Handbook of Curriculum, Pedagogy and Assessment. London: SAGE Publications Ltd

Leat, D., Livingston, K. and Priestley, M. (2013) Curriculum deregulation in England and Scotland Different directions of travel?, in W.Kuiper and J. Berkvens (eds), Balancing Curriculum Regulation and Freedom across Europe, CIDREE Yearbook 2013. Enschede, the Netherlands: SLO. pp.229-248.

McKinsey \& Co. (2007) McKinsey report: How the world's best performing school systems come out on top. Retrieved from http://mckinseyonsociety.com/downloads/reports/Education/Worlds_School_Systems_Final.p $\underline{\mathrm{df}}$

Ministry of Education (1993) The New Zealand Curriculum Framework. Wellington: Learning Media.

Ministry of Education and Culture (MoEC) (2004) Democratic and humane paideia in the Eurocypriot polity. Nicosia, Cyprus: MoEC

Nieveen, N. (2011) Teachers' professional development in curriculum design in the Netherlands, A paper presented at the European Conference for Educational Research, 14 September 2011, Berlin.

OECD (2005) Teachers Matter: Attracting, Developing and Retaining Effective Teachers. OECD, Paris.

Osborn, M., Croll, P., Broadfoot, P., Pollard, A., McNess, E. and Triggs, P. (1997) Policy into practice and practice into policy: Creative mediation in the primary classroom. In G. Helsby and G. McCulloch (eds), Teachers and the national curriculum. London: Cassell. pp.52-65.

Philippou, S. (2014) 'Curriculum Studies' in Cyprus: a research agenda for curriculum, bildung and didaktik as challenges of translation and re-contextualisation. European Journal of Curriculum Studies, 1: 83-99. 
Priestley, M., Biesta, G.J.J., Philippou, S. \& Robinson, S. (2015). The teacher and the curriculum: exploring teacher agency. In D. Wyse, L. Hayward \& J. Pandya (Eds.), The SAGE Handbook of Curriculum, Pedagogy and Assessment. London: SAGE Publications Ltd

Philippou, S., Kontovourki, S. and Theodorou, E. (in press) Professional development for 'professional pedagogues': contradictions and tensions in re-professionalising teachers in Cyprus, in H. Sasser, J. Phillion and J. Rahatzad (eds), Critical multiplicities in teacher education: ethical considerations and alter-globalizations. Information Age Publishers.

Philippou, S., Kontovourki, S. and Theodorou, E. (2014) Can autonomy be imposed? Examining teacher (re)positioning during the ongoing curriculum change in Cyprus, Journal of Curriculum Studies, 46: 611-633.

Priestley, M. (2011a) Whatever happened to curriculum theory? Critical realism and curriculum change, Pedagogy, Culture and Society, 19: 221-238.

Priestley, M. (2011b) Schools, teachers and curriculum change: a balancing act?, Journal of Educational Change, 12: 1-23.

Priestley, M. and Biesta, G.J.J. (eds) (2013) Reinventing the Curriculum: New Trends in Curriculum Policy and Practice. London: Bloomsbury Academic.

Priestley, M., Biesta, G.J.J. and Robinson, S. (2013) Teachers as agents of change: teacher agency and emerging models of curriculum, in M. Priestley and G.J.J. Biesta (eds), Reinventing the curriculum: new trends in curriculum policy and practice. London: Bloomsbury Academic. pp.187-206.

Priestley, M., Biesta, G.J.J. and Robinson, S. (2015) Teacher Agency: An Ecological Approach. London: Bloomsbury Academic.

Priestley, M., Edwards, R., Priestley, A. and Miller, K. (2012) Teacher agency in curriculum making: agents of change and spaces for manoeuvre, Curriculum Inquiry, 43: 191-214.

Priestley, M. and Minty, S. (2012) Developing Curriculum for Excellence: Summary of findings from research undertaken in a Scottish local authority. Stirling: University of Stirling. 
Priestley, M., Biesta, G.J.J., Philippou, S. \& Robinson, S. (2015). The teacher and the curriculum: exploring teacher agency. In D. Wyse, L. Hayward \& J. Pandya (Eds.), The SAGE Handbook of Curriculum, Pedagogy and Assessment. London: SAGE Publications Ltd

Pyhältö, K., Soini, T. and Pietarinen, J. (2012) Do Comprehensive School Teachers Perceive Themselves as Active Professional Agents in School Reforms?, Journal of Educational Change, 13: 95-116.

Sahlberg, P. (2010) Rethinking accountability in a knowledge society, Journal of Educational Change, 11: 45-61.

Scottish Executive (2000) The structure and balance of the curriculum. Dundee: Learning and Teaching Scotland).

Scottish Executive (2006) A Curriculum for Excellence: Progress and proposals. Edinburgh: Scottish Executive.

Sinnema, C. and Aitken, G. (2013) Trends in International Curriculum Development, in M. Priestley and G. J. J. Biesta (eds), Reinventing the curriculum: New trends in curriculum policy and practice. London: Bloomsbury. pp.141-164.

Stoll, L., Bolam, R., McMahon, A., Wallace, M. and Thomas, S. (2006) Professional learning communities: a review of the literature, Journal of Educational Change, 7: 221-258.

Supovitz, J.A. (2008) Implementation as Iterative Refraction, in J.A. Supovitz and E.H. Weinbaum (eds), The Implementation gap: understanding reform in high schools. New York: Teachers College Press. pp. 151-172.

Taylor, M.W. (2013) Replacing the 'teacher-proof' curriculum with the 'curriculum-proof' teacher: Toward more effective interactions with mathematics textbooks, Journal of Curriculum Studies, 45: 295-321.

Vongalis-Macrow, A. (2007) I, Teacher: Re territorialisation of teachers' multi-faceted agency in globalized education, British Journal of Sociology of Education, 28: 425-439. 
Priestley, M., Biesta, G.J.J., Philippou, S. \& Robinson, S. (2015). The teacher and the curriculum: exploring teacher agency. In D. Wyse, L. Hayward \& J. Pandya (Eds.), The SAGE Handbook of Curriculum, Pedagogy and Assessment. London: SAGE Publications Ltd

Wilkins, C. (2011). Professionalism and the post-performative teacher: new teachers reflect on autonomy and accountability in the English school system. Professional Development in Education, 37, 389-409.

World Bank (2014a) Teacher policies in the Republic of Cyprus. Retrieved from: http://www.moec.gov.cy/anakoinoseis/2014/jun_2014.html

World Bank (2014b) Analysis of the Function and Structure of the Ministry of Education and Culture of the Republic of Cyprus. Retrieved from: http://www.moec.gov.cy/anakoinoseis/2014/jun_2014.html

\section{Biographies}

MARK PRIESTLEY is Professor of Education in the School of Education at the University of Stirling. A former History teacher, his research interests relate to the school curriculum, curriculum change, curriculum development and the professional work of teachers. He is currently a member of the Council of the British Educational Research Association and Co-Convener of the European Educational Research Association's Network 3: Curriculum Development. Recent publications include: the edited collection, Reinventing the Curriculum: New Trends in Curriculum Policy and Practice (2013), co-edited with Gert Biesta and Teacher Agency: An Ecological Approach (2015), cowritten with Gert Biesta and Sarah Robinson.

GERT BIESTA (www.gertbiesta.com) is currently Professor of Educational Theory and Policy at the Department of Education and Society, Brunel University London, and Visiting Professor (Art Education) at ArtEZ Institute of the Arts, the Netherlands. He has previously worked at universities in 
Priestley, M., Biesta, G.J.J., Philippou, S. \& Robinson, S. (2015). The teacher and the curriculum: exploring teacher agency. In D. Wyse, L. Hayward \& J. Pandya (Eds.), The SAGE Handbook of Curriculum, Pedagogy and Assessment. London: SAGE Publications Ltd

the Netherlands, England, Scotland, as has had visiting professorships in Sweden, Norway, and England. His research focuses on the theory and philosophy of education, with a particular interest in such areas as democratic citizenship, teaching, teacher education, curriculum, vocational education and adult education. He has also published about the theory and methodology of educational and social research. His latest book, The Beautiful Risk of Education (2014), won the 2014 Outstanding Book Award of the American Educational Research Association (Division B).

STAVROULA PHILIPPOU is a Lecturer in Curriculum and Teaching at the Department of Education, University of Cyprus. She has worked in a variety of educational contexts and as a consultant for UNESCO and the Council of Europe. She is currently the General Assembly Cyprus Representative of the International Association for the Advancement of Curriculum Studies (IAACS) and a Co-coordinator of the 'Curriculum and Teaching' Special Interest Group of the Cyprus Pedagogical Association. Her research interests include: Theory, History and Sociology of Curriculum; Curriculum Change; Teacher Professionalism and Professional Development; European Education Policy; Citizenship Education.

SARAH ROBINSON is an Associate Professor at the Centre for Teaching Development and Digital Media, Faculty of Arts, Aarhus University in Denmark. She is an educational anthropologist whose research interests are entrepreneurship education, policy in practice, curriculum reform, and teacher agency. Currently Sarah is engaged in research in entrepreneurship education in Higher Education, where her primary interest is in teaching development and innovative pedagogies. Sarah has researched and taught in the UK, Denmark and Australia. 
Priestley, M., Biesta, G.J.J., Philippou, S. \& Robinson, S. (2015). The teacher and the curriculum: exploring teacher agency. In D. Wyse, L. Hayward \& J. Pandya (Eds.), The SAGE Handbook of Curriculum, Pedagogy and Assessment. London: SAGE Publications Ltd 